\title{
Detection of new mutations in six out of 10 Swiss HNPCC families by genomic sequencing of the hMSH2 and hMLH1 genes
}

\author{
J-M Buerstedde, P Alday, J Torhorst, W Weber, H Müller, R Scott
}

\begin{abstract}
The cancer predisposition in most HNPCC families is believed to be associated with mutations in the human mismatch repair gene homologues hMSH2 and hMLH1. We searched for mutations in our collection of 10 Swiss HNPCC families by sequencing the exons and exon/intron boundaries of the hMSH2 and hMLH1 genes. In four families we found different mutations which are expected to lead to protein truncations of either the hMSH2 or the hMLH1 proteins owing to premature in frame stop codons or splice defects. In two more families we detected mutations leading to an amino acid deletion and an amino acid substitution in an evolutionary conserved residue respectively. None of these mutations has been reported in other families, which is consistent with the notion that HNPCC associated hMSH2 and hMLH1 mutations are heterogeneous and there is no striking founder effect in the Swiss population. Whenever this could be investigated, the presence of the mutations was confirmed in other family members who showed manifestations of HNPCC. Interestingly, an obligate carrier in one of the families developed a brain tumour at the age of 29 , histologically verified as a glioblastoma multiforme, which was recently linked to HNPCC in the context of Turcot's syndrome.
\end{abstract}

Basel Institute

Grenzacherstrasse 487 , CH-4005 Basel,

Switzerland

J-M Buerstedde

P Alday

Institute of

Pathology,

Kantonsspital,

Schönbeinstrasse 40,

CH-4031 Basel,

Switzerland

J Torhorst

Human Genetics,

Department of

Research,

Kantonsspital

Basel, Hebelstrasse

20, CH-4031 Basel,

Switzerland

W Weber

H Müller

R Scott

Correspondence to: Dr Buerstedde.

Received 9 May 1995

Revised version accepted for

publication 3 July 1995 diagnosed before the age of $50{ }^{3}$ The first to the molecular nature of the disease was provided by the finding that HNPCC tumour colorectal cancer, one of whom is a first de secutive generations are affected, and (3 cells display dinucleotide repeat sequence instability. ${ }^{45}$ Similar instabilities were observed in yeast cells bearing mutations in mismatch repair genes ${ }^{6}$ and it was then shown that the cancer predisposition in some HNPCC families is associated with mutations in the human mismatch repair gene homologues hMSH2 and hMLH $1 .^{7-10}$

We decided to search for mutations in the hMSH 2 and hMLH1 genes in our collection of 10 Swiss families which fulfilled the above criteria (numbered 0434, 1033, 1097, 1121, $1381,1383,1515,1523,1553,1587)$. Linkage analysis was informative only for 1383 and the mutation within the hMSH2 gene of this family has been reported previously. ${ }^{11}$ Family 1383 was nevertheless included in the study as a positive control. We first determined the sequences of all exons and exon/intron boundaries of the hMSH2 2 genes $^{12}$ in all families and then proceeded in those, where no likely mutation was found, with the sequencing of the exons and exon/intron boundaries of the hMLH1 gene. ${ }^{13}$

Genomic DNA was isolated from the blood of one affected family member. PCR amplifications were done in two stages using the primers described previously ${ }^{12}{ }^{13}$ and AmpliTaq (Perkin Elmer) in a $25 \mu \mathrm{l}$ total volume according to the manufacturer's instructions. The second PCR reaction was analysed on a $1 \%$ NuSieve GTG agarose (FMC) gel and the amplified fragments were excised. Direct sequencing of PCR products was done using the solid phase method and Sequenase. Single strand template DNA was isolated using $10 \mu \mathrm{l}$ Dynabeads M-280 Strepavidin (Milan) according to manufacturer's instructions with the following modifications. The salt concentration during the binding step was $10 \times \mathrm{SSPE}$, the washing buffer contained $0 \cdot 17 \%(w / v)$ Triton $\mathrm{X}-100$ and $0 \cdot 1 \mathrm{~mol} / 1 \mathrm{NaCl}$, and the binding step as well as three initial washes were done at $65^{\circ} \mathrm{C}$. The sequencing reaction was according to the Sequenase Dye Primer Sequencing Kit (Perkin Elmer) and the product was analysed on an ABI 373 sequencer. The sequence chromatograms were printed and inspected by eye for signs of sequence heterozygosity. The sequences of hMSH 2 exon 1 and exon 3 contained regions of ambiguity and these exons were also sequenced using Sequitherm (Epicentre Technologies). For unknown reasons sequencing of the coding strands of hMLH1 exon 4, exon 9, and exon 10 did not give satisfactory results and the noncoding strands of these exons were sequenced. 
Table 1 Sequence variation in the coding sequence and the intron/exon boundaries of the hMSH2 and hMLH1 genes

\begin{tabular}{|c|c|c|c|c|}
\hline \multicolumn{5}{|c|}{$h M S H 2$} \\
\hline Exon & Sequence & Description & Family & Likely mutation \\
\hline 3 & АTСТСТСТСAGTTTG $\rightarrow$ ATCTCTCAGTTTGAA & $\begin{array}{l}\text { Deletion of bps } 21-22 \\
\text { Codon } 129 S \rightarrow \text { frameshift } \\
\text { Codon } 131 \rightarrow \text { stop codon }\end{array}$ & $1097 \mathrm{He}^{*}$ & Yes \\
\hline 7 & ACTTCGTCGATTCCC $\rightarrow$ ACTTCGTTGATTCCC & $\begin{array}{l}\mathrm{C} \rightarrow \mathrm{T} \text { transition of bp } 71 \\
\text { Codon } 383 \mathrm{R} \rightarrow \text { stop codon }\end{array}$ & $1587 \mathrm{He}$ & Yes \\
\hline $\begin{array}{l}10 \dagger \\
10\end{array}$ & $\begin{array}{l}\text { CTTCTTGATTATCAA } \rightarrow \text { CTTCTTTATTATCAA } \\
\text { GCAAGTCATTATTAT } \rightarrow \text { GCAAGTCGTTATTAT }\end{array}$ & $\begin{array}{l}\mathrm{G} \rightarrow \mathrm{T} \text { transversion }-8 \text { of } \mathrm{SA}^{*} \\
\mathrm{~A} \rightarrow \mathrm{G} \text { transition }+10 \text { of } \mathrm{SD}^{*}\end{array}$ & $\begin{array}{l}1515 \mathrm{He} \\
0434 \mathrm{He} \\
1033 \mathrm{He} \\
1121 \mathrm{He} \\
1515 \mathrm{He} \\
1381 \mathrm{Ho}^{*}\end{array}$ & $\begin{array}{l}\text { No } \\
\text { No }\end{array}$ \\
\hline 12 & GACACTCAATGATGT $\rightarrow$ GACACTCGATGTGTT & $\begin{array}{l}\text { Deletion of bps } 27-29 \\
\text { Codon } 596 \mathrm{~N} \text { deleted }\end{array}$ & $1383 \mathrm{He}$ & Yes \\
\hline 13 & ATTTGTTTTGTAGGC $\rightarrow$ ATTTGTTCTGTAGGC & $\mathrm{T} \rightarrow \mathrm{C}$ transition -4 of $\mathrm{SA}$ & $\begin{array}{l}1033 \mathrm{He} \\
1121 \mathrm{He}\end{array}$ & No \\
\hline \multicolumn{5}{|c|}{$h M L H 1$} \\
\hline Exon & Sequence & Description & Family & Likely mutation \\
\hline 4 & ATTACAACGAAAACA $\rightarrow$ ATTACAAGGAAAACA & $\begin{array}{l}\mathrm{C} \rightarrow \mathrm{G} \text { transversion of bp } 34 \\
\text { Codon } 117 \mathrm{~T} \rightarrow \mathrm{R}\end{array}$ & $0434 \mathrm{He}$ & Yes \\
\hline 8 & TCGCTCCATCTTTGG $\rightarrow$ TCGCTCCGTCTTTGG & $\begin{array}{l}\mathrm{A} \rightarrow \mathrm{G} \text { transition of bp } 67 \\
\text { Codon } 2191 \rightarrow \mathrm{V}\end{array}$ & $\begin{array}{l}0434 \mathrm{He} \\
1033 \mathrm{He} \\
1515 \mathrm{He}\end{array}$ & No \\
\hline 11 & GAGCGGGTGCAGCAG $\rightarrow$ GAGCGGGCGCAGCAG & $\begin{array}{l}\mathrm{T} \rightarrow \mathrm{C} \text { transition of bp } 93 \\
\text { Codon } 326 \mathrm{~V} \rightarrow \mathrm{A}\end{array}$ & $1515 \mathrm{He}$ & ? \\
\hline 15 & TAAAGTCACTTCATT $\rightarrow$ TAAAGTCGCTTCATT & $A \rightarrow G$ transition -17 of $S A$ & $\begin{array}{l}0434 \mathrm{He} \\
1033 \mathrm{He} \\
1515 \mathrm{He} \\
1553 \mathrm{He}\end{array}$ & No \\
\hline 16 & TGATGAGGTGTGACA $\rightarrow$ TGATGAGTGTGACAG & $\begin{array}{l}\text { Deletion of bp } 165 \\
\text { Codon } 633 \mathrm{E} \rightarrow \text { frameshift } \\
\text { Codon } 636 \rightarrow \text { stop codon? }\end{array}$ & $1033 \mathrm{He}$ & Yes \\
\hline 17 & AGGGACTGCCTATCT $\rightarrow$ AGGGACTTCCTATCT & $\begin{array}{l}\mathrm{G} \rightarrow \mathrm{T} \text { transversion of } \mathrm{bp} 63 \\
\text { No change in codon } 653 \mathrm{~L}\end{array}$ & $1533 \mathrm{He}$ & No \\
\hline 19 & GTTTTCCAGAGTGAA $\rightarrow$ GTTTTCCTGAGTGAA & $\begin{array}{l}A \rightarrow T \text { transversion in first bp of SA } \\
\text { Splice variant downstream of codon } \\
701 Q\end{array}$ & $1121 \mathrm{He}$ & Yes \\
\hline
\end{tabular}

* $\mathrm{SA}=$ splice acceptor site, $\mathrm{SD}=$ splice donor site, $\mathrm{He}=$ heterozygous, $\mathrm{Ho}=$ homozygous

† All our sequences differed from one published sequence ${ }^{11}$ showing $\mathrm{C}$ instead of T at position 4 downstream of the exon 10 splice donor site in the hMSH 2 gene.

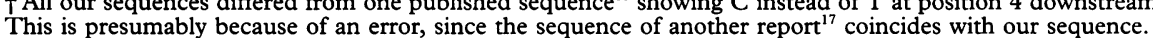

Table 1 lists all the encountered sequence differences in comparison to the published sequences. ${ }^{81112}$ In five families we found five new mutations that are likely to be associated with HNPCC: a 2 bp deletion in hMSH2 exon 3 of 1097 , a $\mathrm{C} \rightarrow \mathrm{T}$ transition in $\mathrm{hMSH} 2$ exon 7 of 1587 , a $\mathrm{C} \rightarrow \mathrm{G}$ transversion in hMLH1
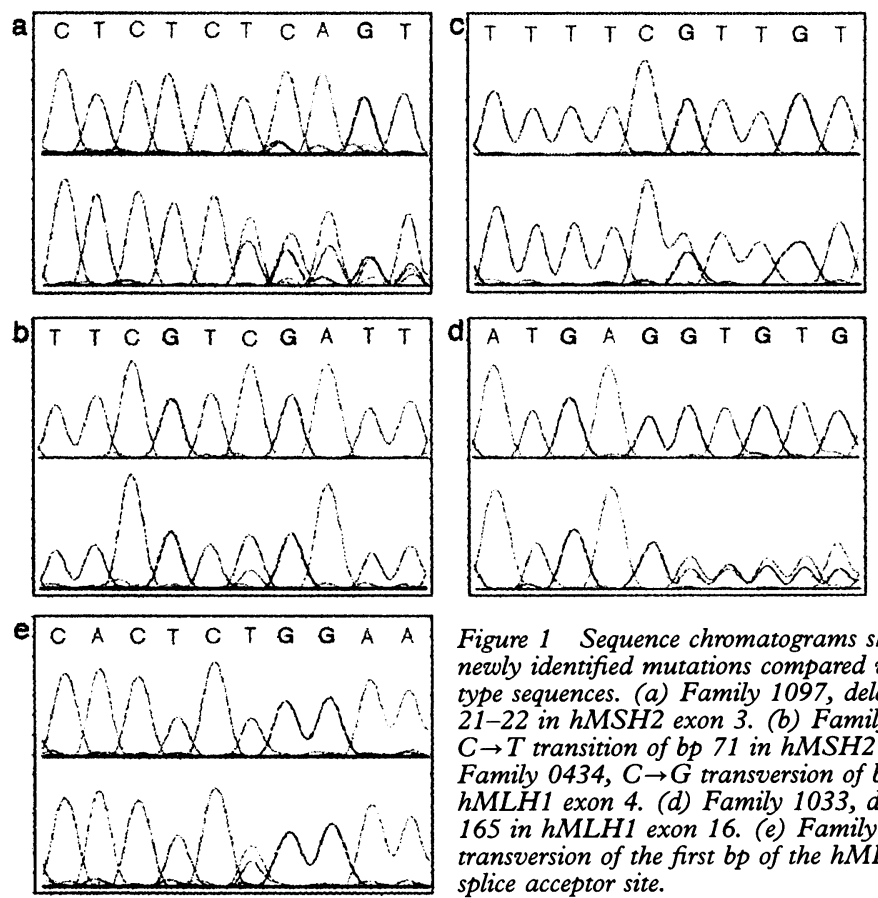

Figure 1 Sequence chromatograms showing the newly identified mutations compared with wild type sequences. (a) Family 1097, deletion of bps 21-22 in hMSH2 exon 3. (b) Family 1587, $C \rightarrow T$ transition of bp 71 in hMSH2 exon 7 . (c) Family $0434, C \rightarrow G$ transversion of bp 34 in $h M L H 1$ exon 4. (d) Family 1033, deletion of bp 165 in $h M L H 1$ exon 16 . (e) Family 1121, $A \rightarrow T$ transversion of the first bp of the hMLH1 exon 19 splice acceptor site. exon 4 of 0434 , a 1 bp deletion in hMLH 1 exon 16 of 1033, and a $\mathrm{A} \rightarrow \mathrm{T}$ transversion in hMLH1 exon 19 of 1121 (fig 1). Four of these mutations are expected to lead to protein truncations of either the hMSH2 or the hMLH1 proteins owing to premature in frame stop codons or splice defects. The mutation in 0434 changes hMLH1 codon 117 , which is conserved between the yeast and human proteins, from threonine into arginine. The significance of another mutation, a $\mathrm{T} \rightarrow \mathrm{C}$ transition in hMLH1 exon 11 of 1515 , remains uncertain, since the resulting amino acid change from valine to alanine could be considered conservative. To our knowledge none of these six mutations has previously been reported, consistent with the notion that HNPCC associated $\mathrm{hMSH} 2$ and $\mathrm{hMLH} 1$ mutations are heterogeneous.

We are currently trying to analyse the segregation pattern of the mutation in family 1515 in detail to clarify its possible association with HNPCC. Two other sequence variants in the coding sequence, the $A \rightarrow G$ transition in hMLH1 exon 8 of 0434, 1033, and 1515, and the $\mathrm{G} \rightarrow \mathrm{T}$ transversion in hMLH1 exon 17 in 1553 are probably unrelated to HNPCC, since the former has been described as a frequent polymorphism ${ }^{14}$ and the latter does not lead to an amino acid change at codon 653 . It also seems unlikely that the base substitutions in the introns upstream and downstream of $\mathrm{hMSH} 2$ exon 10 , downstream of $\mathrm{hMSH} 2$ exon 13 , and upstream of hMLH1 exon 15 impair the 
Table 2 Clinical description of affected family members

\begin{tabular}{|c|c|c|c|c|c|c|}
\hline Family & Patient & Age at diagnosis & Survival time & Tumour site & Mutation & Notes \\
\hline \multirow[t]{7}{*}{1587} & II $\cdot 2$ & Unknown & Unknown & Endometrium & ND & \\
\hline & II $\cdot 3$ & & Unknown & Colon & ND & \\
\hline & III $\cdot 1$ & 44 & $2 \mathrm{y}$ & Colon & ND & \\
\hline & $\mathrm{III} \cdot 2$ & 54 & Unknown & Colon & ND & \\
\hline & III $\cdot 3$ & 56 & $>2 \mathrm{mth}$ & Endometrium & Yes & \\
\hline & III $\cdot 5$ & 41 & $>15 \mathrm{y}$ & Colon & Yes & \\
\hline & III $\cdot 7$ & 36 & $2 y$ & Colon & ND & \\
\hline \multirow[t]{7}{*}{1097} & $\mathrm{I} \cdot 1$ & 46 & Unknown & Colon & ND & \\
\hline & II $\cdot 4$ & 57 & $>5 y$ & Colon & Yes & Hysterectomy at age 52 \\
\hline & $\mathrm{II} \cdot 5$ & 52 & $10 \mathrm{y}$ & Colon & ND & \\
\hline & II $\cdot 7$ & 48 & $>12 \mathrm{y}$ & Rectum & Yes & $\begin{array}{l}\text { Several small adenomas } \\
\text { throughout colon }\end{array}$ \\
\hline & II $\cdot 10$ & 29 & & & & Glioblastoma multiforme \\
\hline & III $\cdot 11$ & $\begin{array}{l}24 \\
43\end{array}$ & $\begin{array}{l}27 \mathrm{y} \\
8 \mathrm{yr}\end{array}$ & $\begin{array}{l}\text { Nasopharynx } \\
\text { Colon }\end{array}$ & $\begin{array}{l}\text { Yes } \\
\text { Multiple }\end{array}$ & \\
\hline & & & & & primaries & \\
\hline \multirow[t]{12}{*}{0434} & $\mathrm{I} \cdot 1$ & 46 & Unknown & Colon & ND & \\
\hline & II $\cdot 2$ & 36 & $1 \mathrm{y}$ & Colon & ND & \\
\hline & II $\cdot 3$ & 47 & $1 \mathrm{y}$ & Colon & ND & \\
\hline & III $\cdot 2$ & $\begin{array}{l}31 \\
32\end{array}$ & $1 \mathrm{y}$ & Brain & ND & No histology \\
\hline & $\mathrm{III} \cdot 4$ & 44 & $10 \mathrm{y}$ & $\begin{array}{l}\text { Colon } \\
\text { Ovary }\end{array}$ & ND & \\
\hline & & 54 & & Ileum & & Adenocarcinoma \\
\hline & $\mathrm{III} \cdot 6$ & 42 & $1 \mathrm{y}$ & Colon & ND & \\
\hline & III $\cdot 7$ & 40 & $>10 y$ & Colon & Yes & Multiple primaries \\
\hline & III $\cdot 9$ & 64 & Unknown & Liver & ND & \\
\hline & $\mathrm{IV} \cdot 2$ & 42 & $1 \mathrm{y}$ & Colon & ND & \\
\hline & IV $\cdot 5$ & 23 & $1 \mathrm{y}$ & Colon & ND & \\
\hline & $\mathrm{V} \cdot 1$ & 31 & $>6 \mathrm{mth}$ & Breast & ND & \\
\hline \multirow[t]{7}{*}{1033} & $\mathrm{I} \cdot 1$ & 41 & $1 \mathrm{y}$ & Colon & ND & \\
\hline & $\mathrm{II} \cdot 2$ & 28 & $2 \mathrm{y}$ & Colon & ND & \\
\hline & $\mathrm{II} \cdot 6$ & 22 & $35 \mathrm{y}$ & Colon & ND & Multiple primaries \\
\hline & $\mathrm{II} \cdot 9$ & 55 & $>7 \mathrm{y}$ & Transverse colon & Yes & \\
\hline & $\mathrm{III} \cdot 2$ & 41 & $>10 y$ & Colon ascendens & Yes & \\
\hline & $\mathrm{III} \cdot \overline{6}$ & 36 & $1 \mathrm{y}$ & Colon & ND & \\
\hline & $\mathrm{III} \cdot 8$ & 18 & Unknown & Colon & ND & Multiple primaries \\
\hline \multirow[t]{11}{*}{1121} & $\mathrm{I} \cdot 1$ & 50 & Unknown & Brain & ND & No histology \\
\hline & $\mathrm{I} \cdot \overline{4}$ & Young age & Unknown & Colon & ND & \\
\hline & $\mathrm{II} \cdot 1$ & & Unknown & Ureta & ND & \\
\hline & $\mathrm{II} \cdot 3$ & 64 & Unknown & Larynx & ND & \\
\hline & $\mathrm{II} \cdot 4$ & 54 & $6 \mathrm{y}$ & Colon & ND & \\
\hline & II $\cdot 6$ & 71 & $1 \mathrm{y}$ & Rectum & ND & \\
\hline & III $\cdot 4$ & 54 & Unknown & Colon ascendens & Yes & Mucinous adenocarcinoma \\
\hline & III 6 & $\begin{array}{l}43 \\
52\end{array}$ & $14 \mathrm{y}$ & Transverse colon & ND & Multiple primaries after \\
\hline & III $\cdot 8$ & 49 & $>5 \mathrm{y}$ & Ovaries & Yes & Mucinous adenocarcinoma \\
\hline & III $\cdot 11$ & 50 & $>5 \mathrm{y}$ & Transverse colon & Yes & \\
\hline & IV $\cdot 15$ & 24 & $>7 \mathrm{y}$ & Transverse colon & Yes & Mucinous adenocarcinoma \\
\hline
\end{tabular}

$\mathrm{ND}=$ not determined.

function of the hMSH2 and hMLH1 genes, since they are not immediately adjacent to splice acceptor or donor sites, and the $T \rightarrow C$ transition upstream of hMSH2 exon 13 as well as the $A \rightarrow G$ transition upstream of hMLH1 exon 15 have previously been reported as sequence polymorphisms. ${ }^{813}$

The pedigrees of the families in which we found the new mutations are shown in fig 2 and the relevant clinical data are listed in table 2 . Whenever this could be investigated, patients with manifestations of HNPCC were shown to carry mutations identical to the ones found in the respective index cases by sequencing the corresponding exons (table 2). Interestingly one obligate carrier in family 1097 (II-10) developed a brain tumour at the age of 29 , histologically verified as a glioblastoma multiforme, which is consistent with a recent re-evaluation of Turcot's syndrome. ${ }^{15}$ Two women in family 1587 (II·2, III-3) developed endometrial cancer, a feature associated with a subset of HNPCC families. ${ }^{1}$ It is currently speculative whether the frequent occurrence of endometrial cancer in some families like this one is the result of the particular mutation or other unknown genetic or environmental influences.

It remains unclear why we were unable to identify mutations in the other families. It is quite possible that the disease is still associated with defects of the hMSH2 or hMLH1 genes, as the gene promoters were not sequenced and deletions of whole exons would not be detected. The disease might also be linked to mutations in additional mismatch repair genes. ${ }^{16}$ Using a slightly different approach Liu et $a l^{17}$ detected hMSH 2 mutations in 10 out of 29 HNPCC families, but in two of the 10 families whole exons were deleted and the mutations could not be identified by genomic sequencing of the exons and exon/intron boundaries. In contrast, Han et al $^{18}$ detected hMLH1 mutations in eight out of 34 unrelated Japanese HNPCC pedigrees. The variable mutation detection rates in these and our studies may reflect the relatively low number of families included or differences in the populations from which these families were collected.

We believe that HNPCC is a disease in which the detection of the causative mutations will be of value for the confirmation of the diagnosis and for presymptomatic testing of at risk family members who would like to know their carrier status. The genomic sequencing approach ${ }^{1213}$ is relatively simple and requires only minute amounts of DNA from one affected family member. Even if it proves to detect mutations in no more than half of the cases, it might be considered as an initial strategy to identify the causative mutations in HNPCC families. 


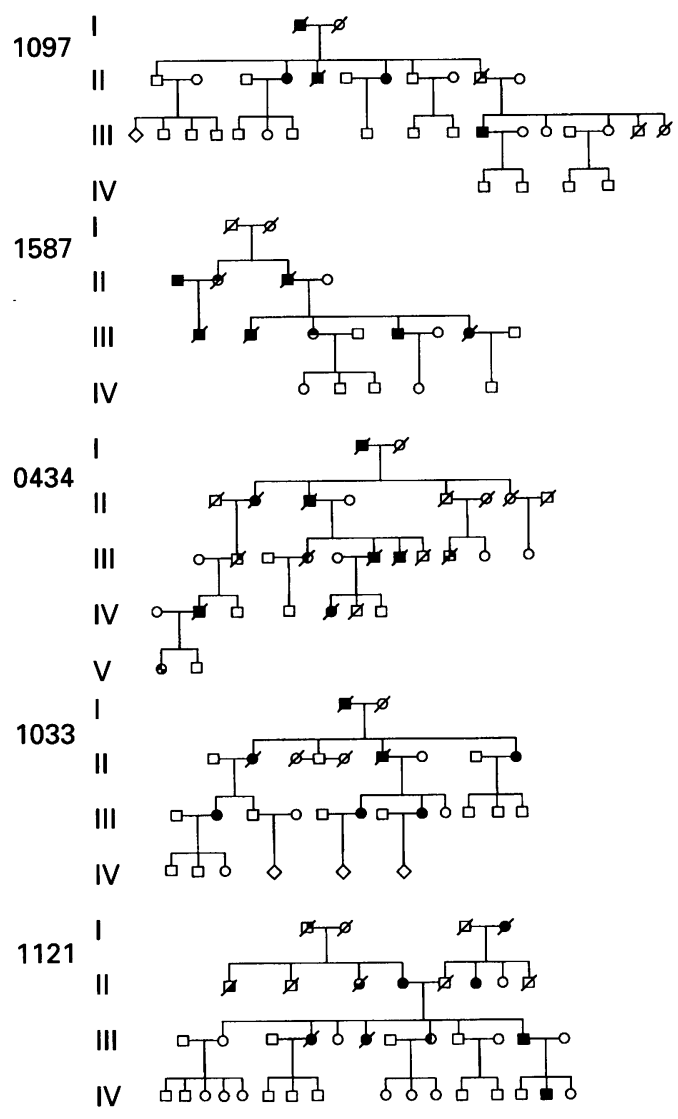

\begin{tabular}{|cccc|}
\hline$\square$ & $\bullet$ & $\bullet$ & $\bullet$ \\
Brain & Colon & Larynx & Ovary \\
$\stackrel{0}{0}$ & $\bullet$ & $\bullet$ & $\square$ \\
Breast & Endometrium & Liver & Ureter \\
\hline
\end{tabular}

Figure 2 Pedigrees of the families in which new HNPCC associated mutations were detected.

We would like to thank Richard Kolodner for the communication of unpublished results and Olga Bezzubova, Hans Frey, Reinhard Stauder, and Shunichi Takeda for critically Frey, Reinhard Stauder, and Shunichi Takeda for critically reading the manuscript. The study was supported by Swiss 5390, and the Swiss Cancer Ligue AKT78. The Basel Institute for Immunology was founded and is supported by F HoffmanLa Roche \& Co Ltd.

1 Lynch HT, Smyrk TC, Watson P, et al. Genetics, natural history, tumor spectrum and pathology of hereditary nonpolyposis colorectal cancer: an updated review. Gastroenterology 1993;104:1535-49.

2 Aaltonen LA, Sankila R, Mecklin JP, et al. A novel approach to estimate the proportion of hereditary nonpolyposis colorectal cancer of total colorectal cancer burden. Cancer Detect Prev 1994;18:57-63.

3 Vasen HFA, Mecklin JP, Meera Khan P, Lynch HT. The International Collaborative Group on Hereditary Nonpolyposis Colorectal Cancer. Dis Colon Rect 1991;34:4245 .

4 Thibodeau SN, Bren G, Schaid D. Microsatellite instability in cancer of the proximal colon. Science 1993;260:816-9. 5 Ionov Y, Peinado MA, Malkhosyan S, Shibata D, Perucho M. Ubiquitous somatic mutations in simple repeated sequences reveal a new mechanism for colonic carcinogenesis. Nature 1993;363:558-61.

6 Strand M, Prolla TA, Liskay RM, Petes TD. Destabilization of tracts of simple repetitive DNA in yeast by mutation affecting DNA mismatch repair. Nature 1993;365:274-6.

7 Fishel R, Lescoe MK, Rao MRS, et al. The human mutator gene homolog MSH2 and its association with hereditary nonpolyposis colon cancer. Cell 1993;75:1027-38.

8 Leach FS, Nicolaides NC, Papadopoulos N, et al. Mutations of a mutS homolog in hereditary nonpolyposis colorectal cancer. Cell 1993;75:1215-25.

9 Papadopoulos N, Nicolaides NC, Wei YF, et al. Mutation of a mutL homolog in hereditary colon cancer. Science 1994;263:1625-9.

10 Bronner CE, Baker SM, Morrison PT, et al. Mutation in the DNA mismatch repair gene homologue hMLH1 is associated with hereditary non-polyposis colon cancer Nature 1994;368:258-61.

1 Mary JL, Bishop T, Kolodner R, et al. Mutational analysi of the hMSH2 gene reveals a three base deletion in family predisposed to colorectal cancer development. Hum Mol Genet 1994;3:2067-9.

12 Kolodner RD, Hall NR, Lipford J, et al. Structure of the human MSH2 locus and analysis of two Muir-Torre kindreds for msh2 mutations. Genomics 1994;24:516-26.

13 Kolodner RD, Hall NR, Lipford JR, et al. Structure of the human MLH1 locus and analysis of a large hereditary human MLH1 locus and analysis of a large hereditary nonpolyposis colorectal carcinom

14 Liu B, Nicolaides NC, Markowitz S, et al. Mismatch repair gene defects in sporadic colorectal cancers with microgene defects in sporadic colorectal cancers with

15 Hamilton SR, Liu B, Parsons RE, et al. The molecular basis of Turcot's syndrome. $N$ Engl f Med 1995;332:839-47.

16 Nicolaides NC, Papadopoulos N, Liu B, et al. Mutation of two PMS homologues in hereditary nonpolyposis colon cancer. Nature 1994;371:75-80.

17 Liu B, Parsons RE, Hamilton SR, et al. hMSH2 mutations in hereditary nonpolyposis colorectal cancer kindreds. Cancer Res 1994:54:4590-4.

18 Han HJ, Maruyama M, Baba S, Park JG, Nakamura Y. Genomic structure of human mismatch repair gene hMLH1, and its mutation analysis in patients with hereditary nonpolyposis colorectal cancer (HNPCC). Hum Mol Genet 1995;4:237-42. 